appearance of hepatitis B surface antigen. Only two of these men had been successfully immunised; the only two men who had become carriers of the hepatitis B virus were nonresponders to the vaccine.

These data must be interpreted in the context of the known relation between disease and age at infection in unimmunised people. Infection in childhood carries the highest risk of persistent viral carriage but a small risk of acute hepatitis. In contrast, adult infection causes acute hepatitis in $30-50 \%$ of people but leads to carriage in fewer than $10 \%$.

Successful immunisation will not result in persistent protective antibody levels and those exposed to infection may be infected, as shown by anticore seroconversion. This will rarely be associated with acute hepatitis. Despite the loss of antibody it seems that people are still protected against becoming carriers of the virus. Clearly, longer follow up of immunised people is needed to guide policy, but currently no reason exists for recommending booster vaccinations as a public health measure. The medical students who believed that vaccination implied lifelong protection may yet turn out to be right. Whether antibody responses after vaccination should be verified and subsequent decay documented, will depend on local resources and individual decisions by both the vaccinator and the person who has been vaccinated.

ANDREW J HALL

Senior lecturer in epidemiology

Communicable Disease Epidemiology Unit,

Department of Epidemiology and Population Sciences,

London School of Hygiene and Tropical Medicine,

London WC1E 7HT

1 Jilg W, Schmidt M, Deinhardt F, Zachoval R. Hepatitis B vaccination: how long does protection last? Lancet 1984;ii:458.

2 Oates BC, Sidebottom AJ, Maxwell SRJ. Efficacy of hepatitis B vaccination: knowledge among clinical medical students. BMf 1993;307:301

3 Stevens CE, Toy PT, Taylor PE, Lee T, Yip H. Prospects for control of hepatitis B virus infection: implications of childhood vaccination and long-term protection. Pediatrics 1992;90:170-3.

Coursaget P, Yvonnet B, Chotard J, Sarr M, Vincelot P, N'Doye R, et al. Seven year study of hepatitis $B$ vaccine efficacy in infants from an endemic area (Senegal). Lancet 1986;ii:1143-5.

Whittle HC, Inskip H, Hall AJ, Mendy M, Downes R, Hoare S. Vaccination against hepatitis B and protection against chronic viral carriage in the Gambia. Lancet 1991;337:747-50.

Fortuin M, Chotard J, Jack AD, Maine NP, Mendy M, Hall AJ, et al. Efficacy of hepatitis B vaccine in the Gambian expanded programme on immunisation. Lancet 1993;341:1129-31.

7 Wainwright RB, McMahon BJ, Bulkow LR, Hall DB, Fitzgerald MA, Harpster AP, et al. Duration of immunogenicity and efficacy of hepatitis $\mathrm{B}$ vaccine in a Yupik Eskimo population. $¥ A M A$ 1989;261:2362-6.

8 Taylor PE, Stevens CE. Persistence of antibody to hepatitis B surface antigen after vaccination with hepatitis B vaccine. In: Zuckerman AJ. Viral hepatitis and liver disease. New York: Alan Liss, 1988:995-7.

9 Hadler SC, Francis DP, Maynard JE, Thompson SE, Judson FN, Echenberg DF, et al. Long-term immunogenicity and efficacy of hepatitis B vaccine in homosexual men. $N$ Engl $尹$ Med 1986;315:209-14.

\title{
Familial colorectal cancer
}

\section{Better understanding of the genetics should mean better screening}

Colorectal cancer causes 25000 deaths each year in Britain, and yet if diagnosed at an early stage it is curable. Some patients with this cancer have a predisposition to the disease, which is inherited as an autosomal dominant. Relatives of these patients would be an ideal group in whom to undertake presymptomatic screening - which should be easier with the recent mapping of a gene to chromosome 2 which, it is claimed, may predispose to up to $15 \%$ of colorectal cancer. ${ }^{12}$

Clinicians are familiar with two relatively common inherited predispositions to cancer of the colon. Familial adenomatous polyposis accounts for about $1 \%$ of colorectal cancer and has a characteristic phenotype: patients with the disorder develop hundreds of adenomatous polyps in the colon during adolescence, and typically they develop colorectal cancer in the fourth decade. The gene responsible (known as APC) was mapped by family linkage analysis to chromosome 5 in 1987. ${ }^{34}$ Further polymorphic markers were then isolated and the gene identified and characterised in $1991 .^{5-8}$ These advances have made it possible to identify unaffected individuals, who do not need screening, and affected individuals in these families before they develop polyposis, when prophylactic colectomy may be offered.

Hereditary non-polyposis colon cancer causes between $5 \%$ and $15 \%$ of colorectal cancer. People with the disorder inherit (as an autosomal dominant) a predisposition to colon cancer and also to endometrial, stomach, biliopancreatic, and urinary tumours. In clinical practice affected families may be defined as those having at least three relatives in two generations with colorectal cancer, one of them having been diagnosed under age 50.9 The individuals with the abnormal gene do not develop numerous polyps but the few adenomatous polyps they do develop seem to undergo a rapid progression of tumourigenesis. ${ }^{10}$ In practice it has often been difficult to distinguish families with hereditary non-polyposis colon cancer-whose members should undergo surveillance colonoscopy - and those in which the clustering was due to chance. Guidance is now, however, becoming available from genetic research.

A group led by de la Chapelle and Vogelstein undertook family linkage analysis in two large, well characterised pedigrees with hereditary non-polyposis colon cancer. ${ }^{1}$ They were able to show tight linkage between a polymorphic DNA marker mapped to chromosome 2 and the development of tumours. The gene responsible has been provisionally named FCC (familial colorectal cancer). Fourteen other pedigrees with the disorder were then analysed for linkage to the same marker on chromosome 2: linkage was excluded in three families, but it was possible in about half the families. These findings may indicate that hereditary non-polyposis colon cancer is heterogeneous, with more than one gene being responsible; the alternative explanation is that some sporadic cases of colorectal cancer may have confounded the linkage analysis.

Several of the events that occur during the development of colorectal tumours have been characterised over the past few years. Tumourigenesis includes the activation of protooncogenes, such as k-ras, and the inactivation of tumour suppressor genes. The site of inactivation of these tumour suppressor genes can often be detected by the loss of genetic material in cancers. In colorectal cancer three tumour suppressor genes known to play a part are the APC gene on chromosome 5, the DCC (deleted in colorectal carcinoma) gene on chromosome 18, and the p53 gene on chromosome 17. Fearon and Vogelstein have proposed a model of sequence of events played by the recognised genes in colorectal tumourigenesis. ${ }^{11}$

No loss of genetic material on chromosome 2 has, however, been found in hereditary non-polyposis colon cancer tumours, and this indicates that the gene on chromosome 2 does not act as a typical tumour suppressor gene. ${ }^{1}$ Other genetic alterations found in hereditary non-polyposis colon cancer tumours were similar to those found in sporadic tumours. A 
surprising observation was that in 11 of 14 familial tumours there were errors in DNA replication not only in the dinucleotide repeat marker on chromosome 2 but throughout the tumour genome, and replication errors also affected trinucleotide repeats, indicating widespread genetic instability. Multiple replication errors have also been found in $13 \%$ of sporadic tumours. ${ }^{1213}$ The tumours with errors were found to have some of the characteristics of familial tumours-they were more frequently right sided and diploid and had a lower frequency of loss of heterozygosity despite there being no characteristic family history. These results suggest that up to $15 \%$ of apparently sporadic tumours may be associated with genetic instability.

Familial colon cancer associated with the gene mapped to chromosome 2 may be one of most common forms of heritable disease in man. It seems to cause errors of DNA replication in tumours. Identification and characterisation of the gene should greatly facilitate surveillance programmes for colon cancer (and associated cancers) in affected individuals and may ultimately permit population screening. Even before the gene is isolated, however, more effort should be made to recognise patients with familial colon cancer so that they and their relatives are managed appropriately. This should probably include screening those at risk from the age of 25 by colonoscopy every three to five years and, in women, by pelvic ultrasonography. Those who develop colorectal cancer should be treated by subtotal colectomy-these patients have a high incidence of metachronous colonic tumours. ${ }^{14}$

HJW THOMAS

St Mary's Hospital,

Senior registrar in gastroenterology

London W2 $1 \mathrm{NY}$

1 Peltomaki P, Aaltonen L, Sistonen P, Pylkkanen L, Mecklin JP, Jarvinen H, et al. Genetic mapping of a locus predisposing to human colorectal cancer. Science 1993;260:810-2.

2 Aaltonen LA, Peltomaki P, Leach FS, Sistonen P, Pylkkanen L, Mecklin JP, et al. Clues to the pathogenesis of familial colorectal cancer. Science 1993;260:812-6.

3 Bodmer WF, Bailey CJ, Bodmer J, Bussey HJR, Ellis A, Gorman P, et al. Localization of the gene for familial adenomatous polyposis on chromosome 5 . Nature 1987;328:614-6.

4 Leppert M, Dodds M, Scambler P, O'Connel P, Nakamura Y, Stauffer D, et al. The gene for familial polyposis coli maps to the long arm of chromosome 5. Science 1987;238:1411-3.

5 Nakamura $Y$, Lathrop $M$, Leppert $M$, Dobbs $M$, Wasmuth J, Wolff $E$, et al. Localization of the genetic defect in familial adenomatous polyposis within a small region of chromosome 5. Am $\mathscr{f}$ Hem 1988 ;3:638-44.

6 Varesco L, Thomas HJW, Cottrell S, Murday V, Fennell SJ, Williams S, et al. CpG island clones from a deletion encompassing the gene for adenomatous polyposis coli. Proc Natl Acad Sci USA 1989;86:10118-22.

7 Kinzler KW, Nilbert MC, Su LK, Vogelstein B, Bryan TM, Levy DB, et al. Identification of FAP locus genes from chromosome 5q21. Science 1991;253:661-5.

8 Groden J, Thliveris A, Samowitz W, Carlson M, Gelbert L, Albertsen H, et al. Identification and characterization of the familial adenomatous polyposis gene. Cell 1991;66:589-600.

9 Vasen HFA, Mecklin JP, Meera Khan P, Lynch HT. The international collaborative group on hereditary non-polyposis colorectal cancer. Dis Colon Rect 1991;34:424-5.

10 Jass JR, Stewart SM. Evolurion of hereditary non-polyposis colorectal cancer. Gut 1992;33:783-6.

11 Fearon ER, Vogelstein B. A genetic model for colorectal tumorigenesis. Cell 1990;61:759-67.

12 Thibodeau SN, Bren G, Schaid D. Microsatellite instability in cancer of the proximal colon. Science 1993;260:816-9.

13 Ionov Y, Peinado MA, Malkhosyan S, Shibata D, Perucho M. Ubiquitous somatic mutations in simple repeat sequences reveal a new mechanism for colonic carcinogenesis. Nature 1993;363: 558-61.

14 Lynch HT, Smyrk TC, Watson P, Lanspa SJ, Lynch JF, Lynch PM, et al. Genetics, natural history, tumour spectrum, and pathology of hereditary nonpolyposis colorectal cancer: an updated review. Gastroenterology 1993;104:1535-49.

\section{Aspirin and colorectal cancer}

\section{Seems to reduce risk}

Aspirin is used to relieve pain, reduce fever, treat arthritis, and prevent heart attacks and stroke. Will it also prevent colorectal cancer?

Four recent epidemiological studies have examined the association between the use of non-steroidal anti-inflammatory drugs (primary aspirin) and colorectal cancer, ${ }^{1-6}$ and in this week's journal, Logan and colleagues describe a casecontrol study of use of aspirin and colorectal adenomas ( $p$ 285). ${ }^{7}$ Their findings increase support for the regular use of aspirin reducing the risk of colorectal cancer. Subjects were recruited from participants performing faecal occult blood tests in a randomised trial of screening for colorectal cancer in Nottingham. Patients whose adenomatous colorectal polyps were diagnosed after a positive faecal occult blood test result were compared with two control groups: those with positive faecal occult blood test results but without adenomas or carcinomas and those who tested negative for faecal occult blood. The relative risk of developing colorectal adenomas for any use of non-steroidal anti-inflammatory drugs was 0.49 compared with the positive controls and 0.66 compared with the negative controls.

Two control groups yielding similar results add credence to the findings. But if controls are generally more health conscious than index patients (their intake of more prescribed drugs suggests that they might see their doctors more frequently and be the "worried well"), the association of use of aspirin with other attributes of a healthy lifestyle might result in the observed lowered risk of colorectal cancer. Also, past treatment for ulcers or indigestion (contraindications to non-steroidal anti-inflammatory drugs) increased the risk of adenomatous polyps by $30-40 \%$ and might explain some of the protection observed among aspirin users. The possibility of selection bias or residual confounding cannot therefore be completely discounted.

All epidemiological studies associating use of aspirin and colorectal cancer or adenomas lack random assignment of subjects to aspirin or placebo. In such studies, casual relations between exposure and disease are identified by consistency, the strength of the association, a dose-response effect, the change in risk after exposure has stopped, and biological plausibility.

The reduction in the risk of colorectal cancer and adenoma among aspirin users occurred in different geographical regions, including Australia, ${ }^{1}$ the United States, ${ }^{23}$ and England. ${ }^{7}$ The association was evident in retrospective casecontrol $^{127}$ and prospective cohort ${ }^{3}$ studies. Furthermore, deaths from colonic cancer ${ }^{3}$ and the incidence of colorectal cancer ${ }^{12}$ and adenomas fell. ${ }^{7}$ Thus the consistency criterion is met. All but one.study, which found no protective effect of aspirin on the incidence of or mortality from colorectal cancer, ${ }^{4-6}$ have estimated that use of aspirin about halves the risk of colonic cancers and adenomas, indicating a strong association.

Little information is available regarding a dose-response effect: only Thun et al reported a significant trend of decreasing risk with increasing frequency of use of aspirin. ${ }^{3}$ Logan and colleagues reported that all categories of usefrom 1-2 to 13 times a year-similarly reduced risk. ${ }^{7}$ Little is known about how risk changes after exposure has stopped: Rosenberg et al reported no protective effect in people who had used aspirin in the past regardless of the duration of use. ${ }^{2}$

How non-steroidal anti-inflammatory drugs inhibit colorectal cancer is not well understood. In animal models, cell cultures, and humans these drugs reduce the concentrations 